\section{Giant Proliferating Trichilemmal Tumor}

Bisher Al-Shanawani, Mukhtar M. Abdelhamid, Feras M. Al-Shomer

Plastic Surgery Division, King Khalid University Hospital, King Saud University College of Medicine, Riyadh, Saudi Arabia

Correspondence: Bisher Al-Shanawani

Plastic Surgery Division, King Khalid University Hospital, King Saud University College of Medicine, PO Box: 18097 Riyadh 11415, Saudi Arabia

Tel: +966-5-5480950, Fax: +966-1-4672552, E-mail: bishersh@ hotmail.com

No potential conflict of interest relevant to this article was reported.

Received: 4 Feb 2013 • Revised: 11 Mar 2013 • Accepted: 3 Apr 2013 pISSN: 2234-6163 • elSSN: 2234-6171

http://dx.doi.org/10.5999/aps.2013.40.4.461 • Arch Plast Surg 2013;40:461-463

Copyright (C) 2013 The Korean Society of Plastic and Reconstructive Surgeons

This is an Open Access article distributed under the terms of the Creative Commons

Attribution Non-Commercial License (http://creativecommons.org/licenses/by-nc/3.o/) which permits unrestricted non-commercial use, distribution, and reproduction in any medium, provided the original work is properly cited.

Proliferating trichilemmal tumors (PTाs) are rare benign neoplasms of follicular linage whose histological hallmark is the presence of trichilemmal keratinization [1]. РTT is thought to originate from the trichilemmal cyst and has the potential for malignant transformation, known as malignant trichilemmal tumor (MPTT) [1]. These lesions may have considerable morbidity and mortality. Recurrence after simple excision is common. The most common site of occurrence is the scalp [2], where the tendency for malignant transformation increases, especially with the presence of infection, ulceration, and rapid enlargement of longstanding nodular scalp lesions together with histological evidence of significant abnormal mitosis, marked cellular pleomorphism, infiltrating margins, and aneuploidy [3]. Diagnosis requires proper histological examination, taking into consideration that such features may not correlate with clinical behavior. MPTT may mimic more aggressive tumors with local recurrence and distant metastasis. Thus, wide local excision of the lesion and long-term followup is recommended.

Here we present a 78-year-old woman with a 35year history of an exophytic growing, painless mass on the occipital scalp area (Fig. 1). It was initially growing slowly and later on started to ulcerate with foul smelling discharge and rapid enlargement that interfered with the patient's daily life, which was the reason for surgical consultation. No history of trauma was noted. The patient was otherwise healthy with no other complaints or symptoms. Written informed consent was obtained from the patient for the purpose

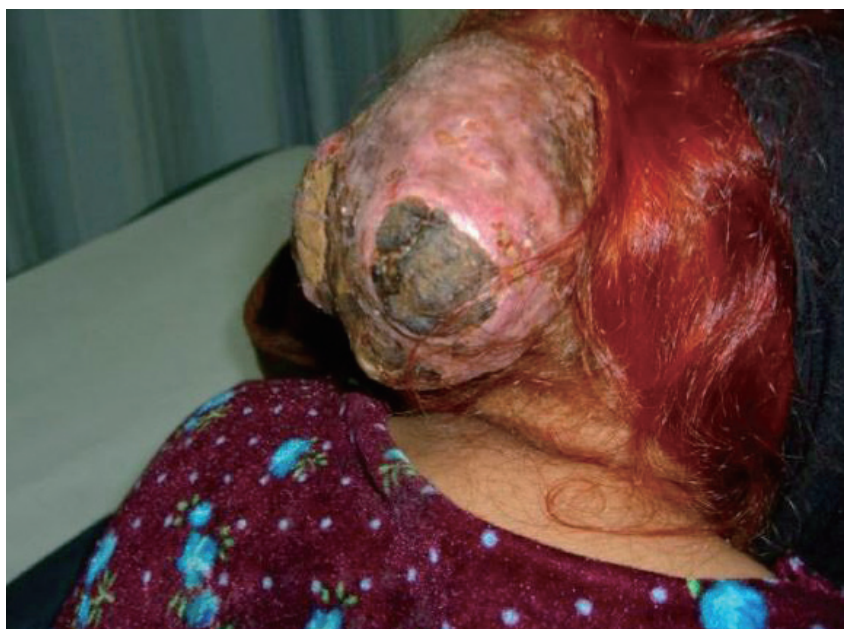

Fig. 1.

Showing the actual scalp lesion undergoing further evaluation in the clinic.

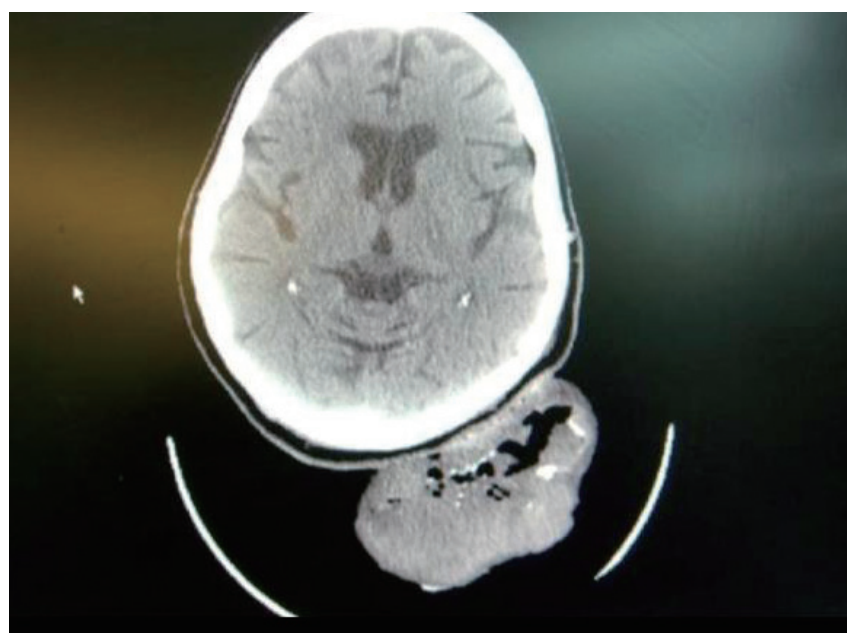

Fig. 2.

Showing the preoperative computed tomography scan of the scalp mass, in which the location is further clarified with the potential of pericranium involvement.

of publication of this case and any accompanying photographs.

A physical examination showed a huge tumoral lesion, oval in shape, situated in the central occipital area slightly to the left side with an irregular surface area. It was associated with ulceration as well as serous discharge but with no bleeding. The mass was solid in consistency, mobile, measuring about $(21 \mathrm{~cm} \times 17 \mathrm{~cm}$ $\times 12 \mathrm{~cm}$ ), and was not covered by hair. The surrounding skin was intact. Further examination revealed no palpable lymph nodes.

A non-contrast-enhanced computed tomography scan of the head was performed to evaluate the un- 


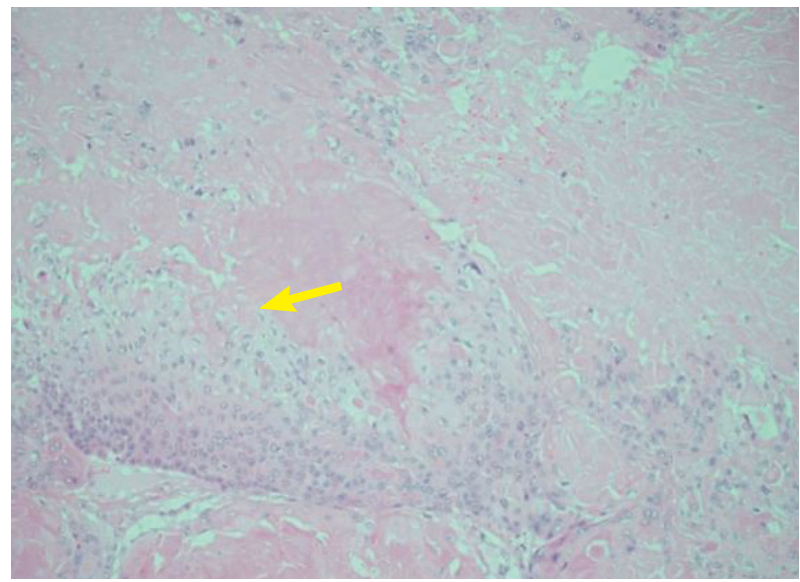

Fig. 3.

A histopathology section that shows the cyst cavity with characteristic amorphous eosinophilic keratin (yellow arrow) $\left(H \& E_{1} \times 100\right)$

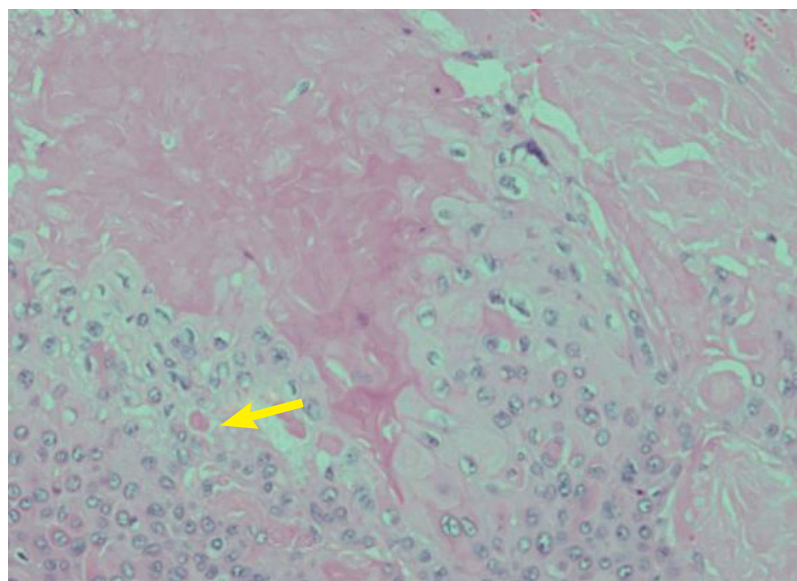

Fig. 4.

A histopathology section showing, under higher magnification, regions of trichilemmal keratinization with variable cytologic atypia (yellow arrow) and mitotic activity together with lobulation of the cyst wall and pilling up of the squamous epithelium $\left(H \& E_{1} \times 200\right)$. derlying extent (Fig. 2), which revealed a soft tissue swelling within the subcutaneous scalp tissue with no bone involvement but with possible pericranium involvement.

The surgical options depending on the pericranium involvement ranged from complete excision and skin grafting as a one stage procedure, excision and rotational flap application, or excision with primary dressing closure and burr holing later with a secondary procedure of skin graft coverage. These options were discussed with the patient who expressed a preference for a single-staged procedure and consented to any of these options depending on the surgeons' intraoperative findings.

Intraoperatively, the mass was managed by complete excisional biopsy under general anesthesia in the prone position. Further exploration showed a com pletely intact pericranium with a clear plane. The

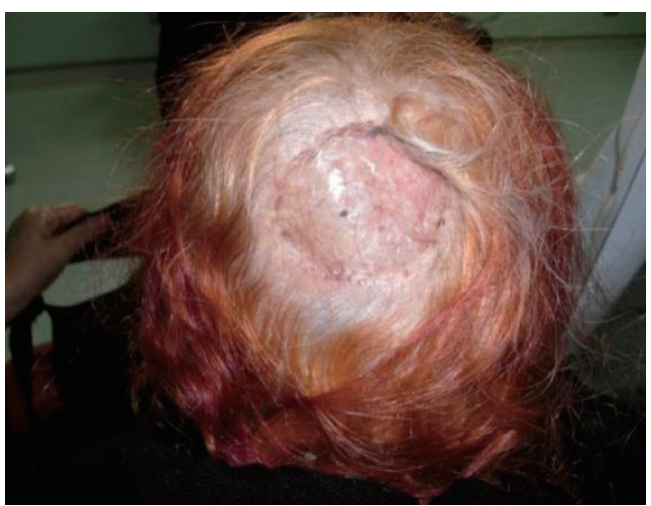

excision was done with a $0.5 \mathrm{~cm}$ clearance area all around as a safety margin with preservation of the pericranium. The defect closure was performed by using a split-thickness skin graft as a coverage solution.

The excised mass was sent for proper histopathologic diagnosis. Hematoxylin and eosin-stained sections of the mass revealed the diagnosis of a proliferating trichilemmal tumor (Figs. 3, 4). The patient was followed closely afterward in the clinic for two consecutive years. Further examination showed good coverage of the defect with no evidence of recurrence either locally or at other sites (Fig. 5).

Management options of PTT generally vary depending on its malignant tendency. Adequate excision with careful assessment of the surgical margins of the tumor is important and required for decreasing the likelihood of recurrence of low-grade malignant PTTs. Also, Mohs micrographic surgery, which ensures precise lesion margin control, can be performed to reduce the recurrence and metastasis rate after tumor resection $[4,5]$. The morbidity and mortality associated with these tumors is represented by their tendency to recur, which was documented in the literature to be around $3.7 \%$, their tendency to metastasize, the difficulty of differentiating them from squamous cell carcinoma, and the recommendations to deal with it as a low-grade malignant carcinoma [5].

This case is special due to its long duration (35 years), together with its location in the scalp with later associated changes including foul smell and ulceration supporting the presence of infection; there 
was no malignant transformation at all, nor any local or distant metastasis. This case is the largest in size ever reported in the literature, measuring $21 \mathrm{~cm} \times 17$ $\mathrm{cm} \times 12 \mathrm{~cm}$. Although the radiological findings suggested the involvement of the pericranium, surgical exploration and the management plan favored simple excision with a free margin and skin graft coverage. During extended follow-up, no signs or symptoms of recurrence were noted. This case illustrates the importance of the knowledge of the patterns of recurrence and the malignant potential of such lesions together with their application to various presentations.

\section{References}

1. Satyaprakash AK, Sheehan DJ, Sangueza OP. Proliferating trichilemmal tumors: a review of the literature. Dermatol Surg 2007;33:1102-8.

2. Anolik R, Firoz B, Walters RF, et al. Proliferating trichilemmal cyst with focal calcification. Dermatol Online J 2008; 14:25.

3. Markal N, Kurtay A, Velidedeoglu H, et al. Malignant transformation of a giant proliferating trichilemmal tumor of the scalp: patient report and literature review. Ann Plast Surg 1998;41:314-6.

4. Poiares Baptista A, Garcia ES, Born MC. Proliferating trichilemmal cyst. J Cutan Pathol 1983;10:178-87.

5. Wang X, Yang J, Yang W. Multiple proliferating trichilemmal tumors in a middle-aged yellow man. Tumori 2010;96:349-51.

\section{Treatment of Atypical Pyoderma Gangrenosum on the Face}

Hyo Hyun Seok, Min Suk Kang, Ung Sik Jin

Department of Plastic and Reconstructive Surgery, Seoul National University College of Medicine, Seoul, Korea

\begin{abstract}
Correspondence: Ung Sik Jin
Department of Plastic and Reconstructive Surgery, Seoul National University College of Medicine, 101 Daehak-ro, Jongno-gu, Seoul 110-744, Korea Tel: +82-2-760-3759, Fax: +82-2-745-5986, E-mail: usj1011@snu.ac.kr

This article was presented as poster at the second Research and Reconstructive Forum on June 1-2, 2012 in Gwangju, Korea.

No potential conflict of interest relevant to this article was reported.

Received: 27 Mar 2013 • Revised: 19 Apr 2013 • Accepted: 7 May 2013 pISSN: 2234-6163 • elSSN: 2234-6171

http://dx.doi.org/10.5999/aps.2013.40.4.463 • Arch Plast Surg 2013;40:463-465

Copyright (C) 2013 The Korean Society of Plastic and Reconstructive Surgeons

This is an Open Access article distributed under the terms of the Creative Commons Attribution Non-Commercial License (http://creativecommons.org/licenses/by-nc/3.0/) which permits unrestricted non-commercial use, distribution, and reproduction in any medium, provided the original work is properly cited.
\end{abstract}

Pyoderma gangrenosum is a rare destructive cutaneous disease characterized by a painful, progressive, and necrotizing wound. Pathologically, pyoderma gangrenosum is a noninfectious neutrophilic dermatitis that usually starts with a sterile pustule, which rapidly progresses to a large painful ulcer with undermined violaceous borders [1].

The treatment of pyoderma gangrenosum has been well reviewed but not established. Conservative management utilizing prolonged, high-dose systemic corticosteroids and other immunosuppressive agents, in addition to gentle local wound care, characterizes traditional treatment of pyoderma gangrenosum.
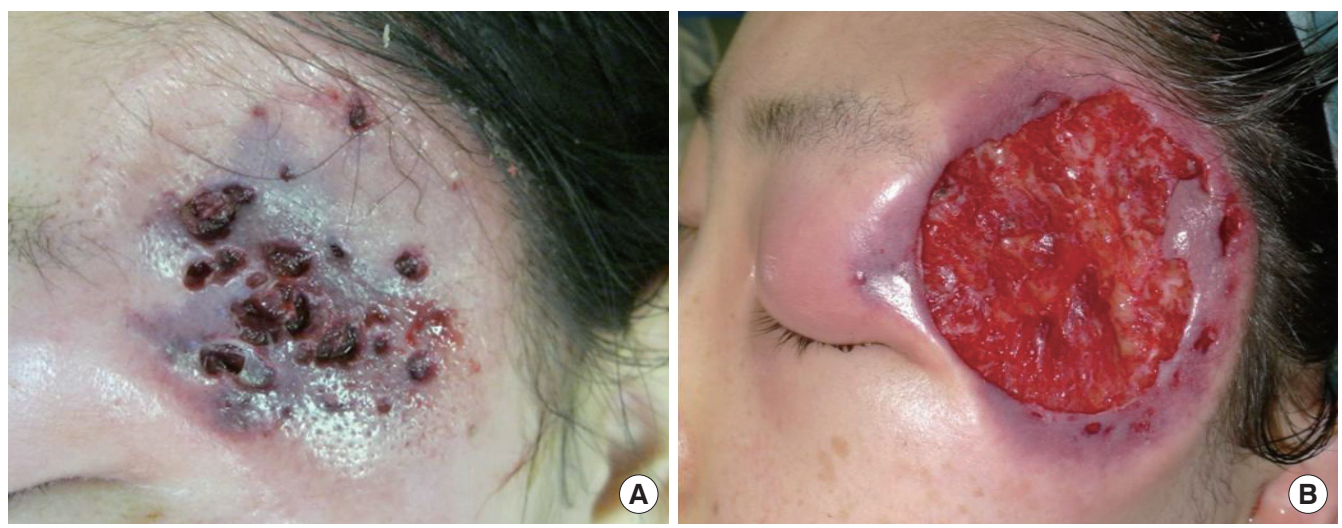

Fig. 1.

Atypical pyoderma gangrenosum on the face. (A) Multiple ulcerative lesions around a reddish-purple margin. (B) Rapidly progressive lesion with ulceration, following serial surgical debridement. 